\title{
A importância do lowa Gambling Task para a psiquiatria
}

The importance of the lowa Gambling Task for psychiatry

Felipe Filardi da Rocha ${ }^{1,2}$, Naira Vassalo Lage

\section{PREZADO EDITOR,}

Foi com grande interesse que lemos o artigo "Estudo de fidedignidade do instrumento neuropsicológico lowa Gambling Task", publicado na última edição do Jornal Brasileiro de Psiquiatria'. Os autores tentam, por meio do método teste-reteste, mostrar a fidedignidade do teste na população brasileira.

A iniciativa é de extrema importância em virtude da crescente utilização do lowa Gambling Task (IGT) na compreensão da neurobiologia do processo de tomada de decisão e na elucidação da fisiopatologia de diversos transtornos psiquiátricos ${ }^{2,3}$. Como sugerido pelos autores, diversos transtornos apresentam baixo desempenho no IGT. Podem-se elaborar diversas hipóteses para essa relação entre os transtornos psiquiátricos e a performance no IGT:

1. Sintomas ansiosos e/ou depressivos concomitantes poderiam alterar o desempenho dos pacientes. Estudos mostram que sintomas depressivos estão associados à maior escolha de cartas desvantajosas, enquanto sintomas ansiosos estariam relacionados a melhor desempenho ${ }^{2,4}$.

2. Alterações neurofuncionais próprias dos transtornos psiquiátricos resultariam direta ou indiretamente em prejuízo no processo de tomada de decisão ${ }^{2,3}$. No caso do transtorno obsessivo-compulsivo, por exemplo, especula-se que o comprometimento do circuito frontoestriatal, principalmente do córtex orbitofrontal, justificaria o desempenho inadequado dos pacientes no teste².

3. O estudo do processo de decisão pode ajudar na formação de fenótipos mais homogêneos, facilitando a realização de estudos genéticos, clínicos, epidemiológicos, entre outros. Nesta perspectiva, nosso grupo de pesquisa, por exemplo, mostrou que o desempenho ruim dos pacientes com TOC está fortemente associado ao polimorfismo do transportador da serotonina (5-HTTLPR), mais especificamente à variante curta².

Contudo, vemos com certo receio a metodologia adotada por Cardoso e colaboradores'. Como citado no artigo, é imprescindível a reaplicação do IGT para avaliação da sua fidedignidade. Ponto extremamente importante no desempenho de indivíduos durante o teste é a percepção de que alguns blocos são desvantajosos em relação a outros. Esse aprendizado, em indivíduos saudáveis, resulta em uma maior escolha de cartas dos blocos vantajosos no decorrer do teste. No final dele, muito pacientes relatam de forma eficaz o reconhecimento dessa característica. Assim, questionamos a validade de repetição do IGT, principalmente em períodos utilizados no estudo que, em alguns casos, foram muito curtos (um mês). Essa

1 Universidade Federal de Minas Gerais (UFMG), Programa de Medicina Molecular, Belo Horizonte, Brasil. 2 Instituto Metropolitano de Ensino Superior, Faculdade de Medicina (IMES).

Endereço para correspondência: Felipe Filardi da Rocha Rua Sapucaia 83, Condomínio Retiro das Pedras - 35460-000 - Brumadinho, MG E-mail: fil_bh@yahoo.com.br 
dificuldade tem sido estudada, buscando-se meios para reaplicação do teste com alteração dos blocos vantajosos ou inversão do objetivo do teste: em vez de programado para uma situação de se obter maior número de dinheiro ao final do teste, opta-se por alteração da programação para que as perdas sejam reduzidas, chegando ao final do teste devendo o mínimo possível. No entanto, faltam estudos para garantir que essas alterações sejam válidas 5 .

Concluímos reforçando o importante papel de estudos envolvendo a neuropsicologia e a psiquiatria, possibilitando novas vertentes de pesquisa para compreensão dos diversos transtornos psiquiátricos.

Declaramos não haver conflitos de interesse.

\section{REFERÊNCIAS}

1. Cardoso CO, Carvalho JCN, Cotrena C, Bakos DGC, Kristensen CH, Fonseca RP. Estudo de fidedignidade do instrumento neuropsicológico lowa Gambling Task. J Bras Psiquiatr. 2010;59(4):279-85

2. Da Rocha FF, Malloy-Diniz L, Lage NV, Romano-Silva MA, De Marco LA, Correa H. Decisionmaking impairment is related to serotonin transporter promoter polymorphism in a sample of patients with obsessive-compulsive disorder. Behav Brain Res. 2008;195(1):159-63.

3. Da Rocha FF, Malloy-Diniz L, De Sousa KC, Prais HA, Correa H, Teixeira AL. Borderline personality features possibly related to cingulate and orbitofrontal cortices dysfunction due to schizencephaly. Clin Neurol Neurosurg. 2008;110(4):396-9.

4. Manes F, Sahakian B, Clark L, Rogers R, Antoun N, Aitken M, et al. Decision-making processes following damage to the prefrontal cortex. Brain. 2002;125(Pt 3):624-39.

5. Buelow MT, Suhr JA. Construct validity of the lowa Gambling Task. Neuropsychol Rev. 2009;19(1):102-14. 